hand with learning to reconstruct the series (that is to summon $\mathbf{I}$, 2, 3, when zeb, kag, lef, etc. are given, all other conditions of the experiment of the experiment being identical) and on the other with learning the series by merely rereading them.

Incidentally evidence was secured to show that the degree of ability to image smells bore no considerable relation to ability to remember the series containing them, that the exclusion of secondary associations and other means of adding significance to the bare series of smells, colors and nonsense syllables is practically impossible unless the series are presented very, very rapidly or the experiment is wilfully turned into an experiment in inhibiting all natural movements of the mind; that variations in efficiency in memorizing are related to variations in amount of mental work done without rest chiefly through the variations in interest caused thereby.

Of dependence on verbal rather than concrete imagery the author notes that "The figures at their face value seem to show that the subjects who depend most on concrete imagery learned worst." The complexity of the conditions, especially degree of practice, prevented a precise estimate of the correlation. Space forbids mention of others of the many noteworthy observations.

EDward L. Thorndike.

Teachers College, Columbia University.

\title{
TACTUAL SPACE
}

Die taktile Schätzung von ausgefüllten und leeren Strecken. HELEN Dodd Cook. Reprint from the Arch.f. d. ges. Psychol., 19ro, 16, 3 u. 4 Hft. Pp. 130.

All tests were made with 'passive' stimulation, i. e., the two extents for each comparison were applied to the passively resting arm of the subject, all movement of the arm itself or of the stimulating object along the skin being excluded. The stimuli were applied longitudinally on the volar surface of the forearm, about in the middle. Subjects were kept, where possible, in ignorance of the results, methods etc. In all, sixteen subjects were used. In each test the subject was to compare the length of a 'Vergleichsstrecke' (V) with that of a 'Normalstrecke' (N.).

PART I, the 'successive' form of 'passive' procedure. 'The stimulating points were hard rubber pegs, each tapering to an area I $\mathrm{mm}$. in diameter; for 'filled' (ausgefüllte $=\mathrm{A}$ ) extents the distance between centres of the pegs could be varied from .5 to $3.5 \mathrm{~cm}$; for unfilled 
(leere $=\mathrm{L}$ ) extents only the end-pegs were, of course, utilized. The stimulus was applied by means of a handle held by the experimenter, the two extents to be compared ( $N$ ranging from 4 to $14 \mathrm{~cm}$.) being given successively, the second parallel to and about $.3 \mathrm{~mm}$. distant from the first. The method of minimal changes was employed. The chief result was that all A-extents from 6 to $14 \mathrm{~cm}$. were, in comparison with L-extents, underestimated, and this whether the time order of application of stimuli was NV or VN. Introspection showed that the illusion was much influenced by the subjective distinctness or insistence of the 'filling-points' (Füllspitze) and attention to the end-points, the former disturbing the latter so as to conceal or minimize the felt difference between the limiting points. Further, whereas Rieber had found that the A-extents, although underestimated when short, were overestimated when long, Cook found no such reversal of the illusion at all. Rieber had explained the underestimation by a 'fusion' of the points when near together, but Cook shows that the maximum underestimation coincides with the maximum subjective distinctness of the points $(2 \mathrm{~cm}$. apart).

PART II. In this second and weightiest part of her experiments Cook used an aesthesiometric balance, one arm carrying the aesthesiometer proper, overbalanced, on the other arm, by weights in the balance pan which, when released, allowed the stimulating points carried by the first arm to descend, until mechanically arrested, with the required pressure on the arm. The points were gauged Chinese pig bristles from .105 to .110 mm. diameter. By special devices these were each vertically adjustable so that the whole row of bristle points could be set to conform to the shape of the volar surface of the forearm, and horizontally adjustable so as to secure any desired distance between bristles. Furthermore, any of the bristle holders could be, either singly or in groups, eliminated from the stimulus row, thus allowing, for successive stimuli, a fairly quick shift (6 to Io sec.) from an $A$ to an $L$ or vice versa. The arm in this series lay in a plaster form and a row of about equally sensitive points, $5 \mathrm{~cm}$. apart and parallel to the longitudinal axis of the arm, was marked for stimulation.

The 'simultaneous' form of 'passive' procedure. $\mathrm{N}$ and $\mathrm{V}$ were simultaneously applied, not side by side, but end to end $\left(\Delta^{\Delta}{ }^{L}\right.$.). The method of constant stimuli was employed. The subject was required to say whether $V$ was larger than, equal to, or smaller than $N$. The N-extents were 4,6 and $8 \mathrm{~cm}$. in length and the points .5 , I and $2 \mathrm{~cm}$. apart. General results: (I) The AN-extents were over- 
estimated, the $\mathrm{LN}$ underestimated, i. e. an A-extent was always overestimated; (2) this overestimation of A-extents did not result from visual images (Gesichtsvorstellungen) but, since it was just as great in two blind subjects as in strongly visual subjects, it was a tactual phenomenon; (3) if the attention was more strongly focused on one of the extents it was, in comparison with the less strongly focused, overestimated; (4) if the basis of judgment was the immediate impression of extent (unmittelbarer Streckeneindruck), the amount of illusion increased with increasing length of $\mathrm{N}$; when other factors entered, the reverse was the case; (5) the influence of the number of 'filling-points' was not immediate nor uniform for different subjects but depended on how the extents were apperceived ( $A$ uffassungsweise). The constant overestimation of the A-extents in this group differs again from the results of Rieber, who found underestimation for short distances and overestimation for long; it was this particular form of simultaneous stimuli (end to end extents) that Rieber used.

The 'successive' form of 'passive' procedure. Practically the same procedure as in the experiments of Part I except that the aesthesiometric balance and the method of constant stimuli were used. $R e-$ sults: (I) an A-extent was, compared with an L-extent, underestimated. This result agrees with that in Part I above and both differ from the results of the foregoing 'simultaneous' stimulation. The direction of the illusion appears, therefore, to be dependent on the manner in which the stimuli are presented; (2) the illusion was greater when the 'filling-points' were closest together $(.5 \mathrm{~cm}$.). This fact does not, however, thinks Cook, argue in favor of Rieber's theory of 'fusion' (see Part I) and against her own result that the degree of illusion of this type increases with the distinctness of the points, since introspection showed in this case that the points most distinctly felt were those closest together. In short, the distinctness of the points is not uniformly a function merely of their increasing distance apart; on what it does depend is not yet determined.

Combination of the previous two procedures. In this group the stimuli extents were also successively applied but were spatially placed end to end with, however, a space of $.5 \mathrm{~cm}$. between their adjacent ends, so as to avoid stimulating the same end point twice. The result was that when an L- and an A-extent were compared, there was either no illusion, or one quite minimal. This result, along with the previous findings with successive stimuli, shows that in successive stimulation with $\mathrm{A}$ - and L-extents the advantage of $\mathrm{A}$ as an impression of extent (Streckeneindruck) over $\mathrm{L}$ is greatly reduced. 
It is a matter of regret that space precludes further discussion of this careful, and, in inferences, conservative piece of experimental analysis. The author reaches the general conclusion that the distribution of the attention between the two extents or within either extent doubtless most influences the judgments; she represents essentially, therefore, an 'Aufmerksamkeitstheorie.'

YALE UnIVERSITY

Roswell P. Angier

\section{MENTAL HEALING}

Three Thousand Years of Mental Healing. George Barton Cutten.

New York: Charles Scribner's Sons, 1911. Pp. viii +318.

President Cutten has given us in this book a most extensive and excellently arranged compilation of the phases and practices of the healing art which we now know as 'mental.' The volume is not for the specialist in these matters, the text being predominantly expository and "dealing more especially with the historical side of the subject."

Stating the common law underlying all forms of mental healing to be: "My body tends to adjust itself so as to be in harmony with my ideas concerning it," and pointing out that there is no 'best form' of mental healing, the author proceeds to show that the diversity of means employed throughout the ages has been such as to meet the wide diversities of custom, belief, and inherited superstition that at any given moment were prevailing.

From the early practices in Egypt and in India, among the Jews and among the Greeks, the reader is carried through successive ages down to the various cults of the present day. In general the association of mental healing with religion is held to have been advantageous, since "the devout attitude of mind is one most favorable for the working of suggestion." The twofold influence of the church, on the one hand in increasing human effort in alleviating illness and on the other in perpetuating the easy superstitions of mankind and thus delaying the development of medical science, is well set forth. The non-religious 'healer,' it is pointed out, has been more ready to recognize the limitations of his power and has thus been less obstructive to advances in the healing art than his confrère who has worked in the name of religion.

Separate chapters - and these perhaps the best of the bookare devoted to 'Relics and Shrines,' 'Talismans,' 'Amulets,' and 